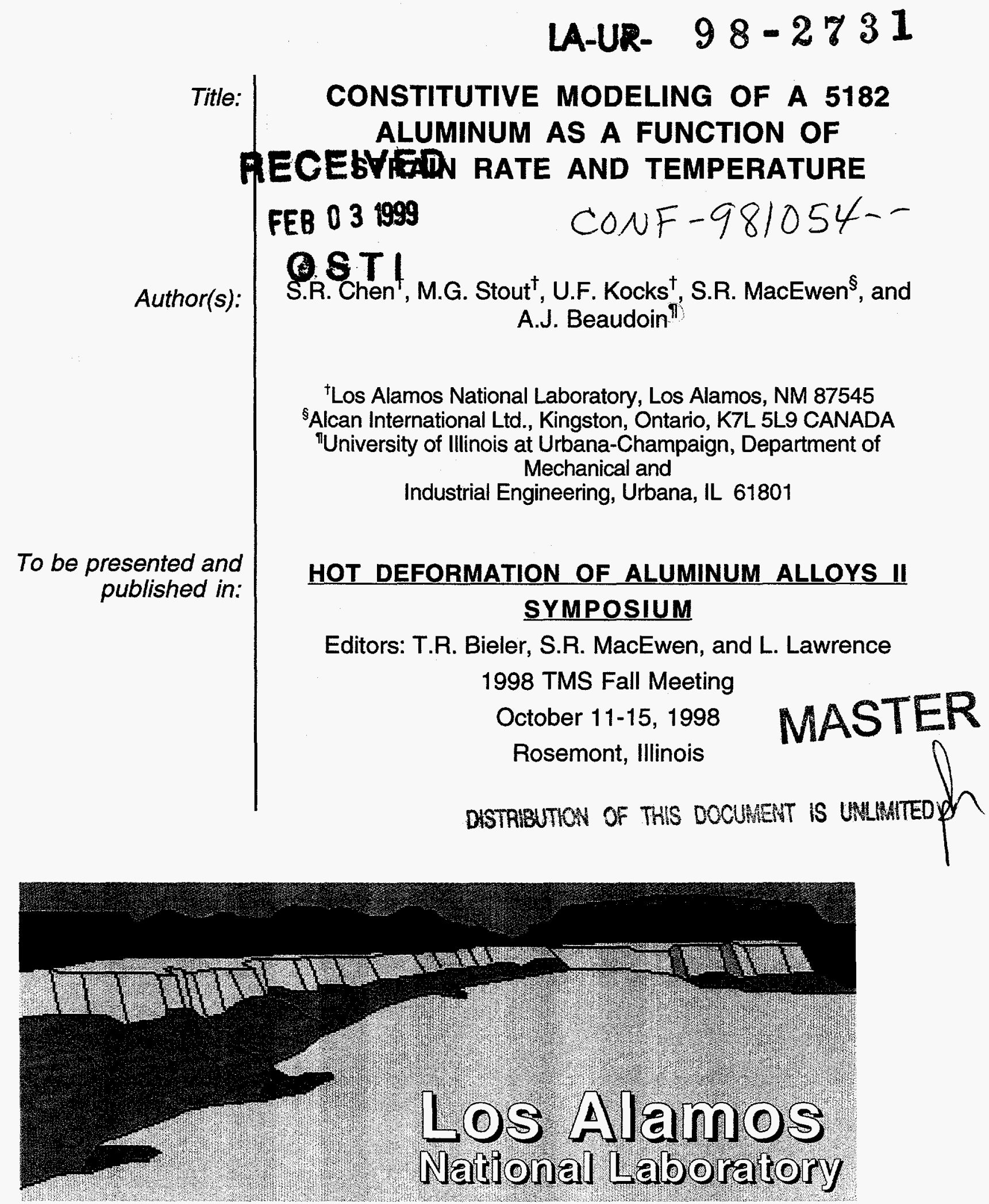

Los Alamos National Laboratory an affirmative action/equal opportunity employer is operated by the University of California for the U.S. Department of Energy under contract W-7405-ENG-36. By acceptance of this article, the publisher recognizes that the U.S. Government retains a nonexclusive, royalty-free license to publish or reproduce the published form of this contribution, or to allow others to do so, for U.S. Govemment purposes. The Los
Alamos National Laboratory requests that the publisher identify this article as work performed under the auspices of the U.S. Department of Energy. Alamos National Laboratory requests that the publisher identify this article as work performed under the auspices of the U.S. Department of Energy.
This is a preprint of a paper intended for publication in a journal or proceedings. Because changes may be made before publication, this preprint is made available with the understanding that it will not be cited or reproduced without the permission of the author. 


\section{DISCLAIMER}

This report was prepared as an account of work sponsored by an agency of the United States Government. Neither the United States Government nor any agency thereof, nor any of their employees, makes any warranty, express or implied, or assumes any legal liability or responsibility for the accuracy, completeness, or usefulness of any information, apparatus, product, or process disclosed, or represents that its use would not infringe privately owned rights. Reference herein to any specific commercial product, process, or service by trade name, trademark, manufacturer, or otherwise does not necessarily constitute or imply its endorsement, recommendation, or favoring by the United States Government or any agency thereof. The views and opinions of authors expressed herein do not necessarily state or reflect those of the United States Government or any agency thereof. 


\section{DISCLAIMER}

Portions of this document may be illegible in electronic image products. Images are produced from the best available original document. 


\title{
CONSTITUTIVE MODELING OF A 5182 ALUMINUM AS A FUNCTION OF STRAIN RATE AND TEMPERATURE
}

\author{
S.R. Chen ${ }^{\dagger}$, M.G. Stout ${ }^{\dagger}$, U.F. Kocks ${ }^{\dagger}$, S.R. MacEwen ${ }^{\S}$, and A.J. Beaudoin ${ }^{\mathbb{I}}$ \\ ${ }^{\dagger}$ Los Alamos National Laboratory, Los Alamos, NM 87545 \\ ${ }^{\S}$ Alcan International Ltd., Kingston, Ontario, K7L 5L9 CANADA \\ ${ }^{\mathbb{I}}$ University of Illinois at Urbana-Champaign, Department of Mechanical and \\ Industrial Engineering, Urbana, IL 61801
}

\begin{abstract}
We have measured the stress/strain response of a 5182 aluminum alloy as a function of strain rate and temperature. As one expects, at room temperature and quasi-static strain rate this alloy exhibits dynamic strain aging with negative strain-rate sensitivity. At higher temperature, we have separated the response into two categories, when the material displays a yield drop and when it does not.

The yield drop was only observed if the yield stress was below 70MPa. In this case the work-hardening curve was for practical purposes flat. Within this regime the deformation has been labeled "Class A" behavior. It occurs by continuous motion of dislocations accompanied by diffusion of solute. It is further shown that a constitutive relation such as $\dot{\varepsilon}=A(\sigma / \mu)^{n} \cdot \mu b^{3} / k T \cdot \exp \left(-Q_{D} / k T\right)$ is appropriate to describe deformation in this temperature/ strain-rate regime where the solute drag mechanism dominates. In this expression $Q_{D}$ is the activation enthalpy for self diffusion of $\mathrm{Mg}$ in aluminum, which is $131 \mathrm{~kJ} / \mathrm{mol}$.

In the high-stress regime, where the yield stress is above $80 \mathrm{MPa}$, there is positive work hardening associated with flow stress behavior of the 5182 alloy. The yield stress was nearly constant; however, the hardening and saturation flow stress increases with decreasing temperature and increasing strain rate. In this regime the deformation is dominated by dislocation accumulation and dynamic recovery. We have found that the Mechanical Threshold Strength (MTS) model accurately describes the constitutive response as a function of temperature and strain rate.
\end{abstract}




\section{Introduction}

The widespread utilization of modern high-speed computers makes it possible to develop more sophisticated material constitutive model descriptions capable of modeling complex problems ${ }^{[1,2]}$. An accurate description of a materials response over a wide range of loading environments, as well as having predictive capabilities outside the measured range, is in great demand. Hot rolling is a particularly challenging aspect of the rolling process to simulate because of the wide range of temperatures over which the process occurs. In addition, one expects that the ingot experiences several orders of magnitude difference in strain rates as well. These widely varying conditions represent a particular challenge for constitutive modeling. We will examine the applicability of a physically-based flow stress model, namely the Mechanical Threshold Strength model[3], in representing the mechanical behavior of a 5182 aluminum-magnesium-manganese alloy in the thermal recovery regime. We will also adopt a power-law constitutive relation, which is widely used in describing steady-state stress observed in many solid solution alloys during creep ${ }^{[4-6]}$, in the high-temperature regime where solute drag is the dominant deformation mechanism.

\section{Experimental}

\section{$\underline{\text { Materials }}$}

A 5182 aluminum-magnesium-manganese alloy was investigated in this study. The constitutive responses of transfer-gauge material were measured in compression at various temperatures and strain rates. The transfer gauge material was a plate of $25.4 \mathrm{~mm}$ in thickness. Right-cylindrical compression specimens with a $1: 1.33$ aspect ratio, $12.7 \mathrm{~mm}$ in height and $9.5 \mathrm{~mm}$ diameter, were machined from the center of the transfer gauge. Specimens were cut in two orientations: compression axis parallel to the rolling direction, and compression axis aligned with the plate normal direction. A recess, to trap lubricant, was machined into both ends of the specimens in a manner originally used by Rastegaev ${ }^{[7]}$. The recess was $0.25 \mathrm{~mm}$ deep and the ring remaining around the edge of the specimen was $0.5 \mathrm{~mm}$ wide. A mixture of vacuum grease and colloidal graphite served as lubricant up to $400^{\circ} \mathrm{C}$. For the higher-temperature tests, a lead borosilicate glass powder with a softening point around $440^{\circ} \mathrm{C}$ was used. These procedures assured uniform deformation to large strains. Two platens made of UDIMET $700,25 \mathrm{~mm}$ in height, were heated using two 400-Watt cartridge heaters in each. The platens were assembled on top of larger stainless platens which were cooled by a constant flow of $18^{\circ} \mathrm{C}$ water. A stainless steel tube was used to form a chamber. This arrangement allowed the temperature to be maintained accurate to within $\pm 2{ }^{\circ} \mathrm{C}$, and the sample to be quenched into water within 2 seconds after each test. Compression tests were performed at temperatures between $22^{\circ} \mathrm{C}$ and $550^{\circ} \mathrm{C}$ in air and strain rates of $10^{-3} \mathrm{~s}^{-1}$ and $1 \mathrm{~s}^{-1}$. The stress/strain response was calculated from load and crosshead displacement. A single-arm extensometer was used to control an MTS servohydraulic test frame with better resolution and accuracy in displacement measurement.

\section{Description of Constitutive Models}

\section{Regime of Thermal Recovery and the Mechanical Threshold Strength (MTS) Model}

Plastic deformation is known to be controlled by interactions of dislocations with obstacles. These interactions are in general thermally activated. In the MTS model, the current structure of a material is represented by an internal state variable, the mechanical threshold, which is defined as the flow stress at $0 \mathrm{~K}$. The mechanical threshold is separated into athermal and thermal components:

$$
\hat{\sigma}=\hat{\sigma}_{a}+\sum \hat{\sigma}_{t}
$$

where the athermal component $\hat{\sigma}_{a}$ characterizes the rate independent interactions of dislocations with long-range barriers such as grain boundaries, dispersoids, or second phases. The thermal component $\hat{\sigma}_{t}$ characterizes the rate dependent interactions, that can be overcome with the assistance of thermal activation, of dislocations with short-range obstacles (forest dislocations, 
interstitial, solutes, Peierls barrier, etc.). The flow stress of a constant structure at a given deformation condition is expressed in terms of the mechanical threshold as:

$$
\frac{\sigma}{\mu}=\frac{\sigma_{a}}{\mu}+\sum S(\dot{\varepsilon}, T) \frac{\hat{\sigma}_{t}}{\mu_{0}}
$$

where the athermal component is a function of temperature only through the shear modulus, and the factor $S$ specifies the ratio between the applied stress and the mechanical threshold stress. This factor is smaller than 1 for thermal-activation controlled glide because the contribution of the thermal activation energy reduces the stress required to force a dislocation past an obstacle. For single-phase cubic materials, we have found that the thermal component $\left(\hat{\sigma}_{t}\right)$ can be simplified by the linear summation of a term describing the yield stress $\left(\hat{\sigma}_{i}\right)$ and a second term describing the evolution of the dislocation structure $\left(\hat{\sigma}_{\varepsilon}\right)$ as a function of temperature, strain rate and strain. Equation 2 can be rewritten as:

$$
\frac{\sigma}{\mu}=\frac{\sigma_{a}}{\mu}+S_{i}(\dot{\varepsilon}, T) \frac{\hat{\sigma}_{i}}{\mu_{0}}+S_{\varepsilon}(\dot{\varepsilon}, T) \frac{\hat{\sigma}_{\varepsilon}}{\mu_{0}} .
$$

In the thermally-activated glide regime, the interaction kinetics for short-range obstacles are described by an Arrhenius expression of the form:

$$
\dot{\varepsilon}=\dot{\varepsilon}_{0} \exp \left(\frac{-\Delta G}{k T}\right)
$$

The free energy $(\Delta G)$ is a function of stress, and a phenomenological relation of the following form has been chosen ${ }^{[8]}$ :

$$
\Delta G=g_{0} \mu b^{3}\left[1-\left(\frac{\sigma_{t} / \mu}{\hat{\sigma}_{t} / \mu_{0}}\right)^{p}\right]^{q}
$$

Upon rearrangement, we have the following relation between the applied stress and the mechanical threshold stress at a constant structure:

$$
\frac{\sigma_{t}}{\mu}=\left[1-\left(\frac{k T}{g_{0} \mu b^{3}} \ln \frac{\dot{\varepsilon}_{0}}{\dot{\varepsilon}}\right)^{1 / q}\right]^{1 / p} \cdot \frac{\hat{\sigma}_{t}}{\mu_{0}} \equiv S_{t} \cdot \frac{\hat{\sigma}_{t}}{\mu_{0}} .
$$

The second term on the right-hand side of the equation 3 describes the rate dependence of the yield stress mainly due to intrinsic barriers, such as the strong Peierls stress in BCC materials at low temperature or high strain rate; it is further assumed that this term does not evolve after yielding. The structure term $\left(\hat{\sigma}_{\varepsilon}\right)$ in equation 3 evolves with strain due to dislocation accumulation (work hardening) and annihilation (recovery). This structure evolution $\theta=d \hat{\sigma}_{\varepsilon} / d \varepsilon$ is represented by a competition between the hardening $\left(\theta_{0}\right)$ due to dislocation accumulation and softening $\left(-\theta_{r}\right)$ resulting from dynamic recovery (dislocation annihilation and rearrangement), and is written as:

$$
\theta=\theta_{0}-\theta_{r}(T, \dot{\varepsilon}, \hat{\sigma})
$$

The physical understanding of the work hardening behavior of polycrystals is still inadequate to unify this complex process and represent it entirely by physically-based parameters. For this project we have chosen the following form to fit the experimental hardening data: 


$$
\frac{\theta}{\mu}=\frac{\theta_{0}}{\mu_{0}} \cdot\left[1-\frac{\hat{\sigma}-\hat{\sigma}_{y}}{\kappa \hat{\sigma}_{v}}\right]^{\kappa}=\frac{\theta_{0}}{\mu_{0}} \cdot\left[1-\frac{\hat{\sigma}_{\varepsilon}}{\hat{\sigma}_{\varepsilon s}}\right]^{\kappa}
$$

where $k=1$ represents a linear variation of strain hardening rate with stress (Voce law). The saturation threshold stress $\hat{\sigma}_{\varepsilon s}$, defined as $\kappa \hat{\sigma}_{v}$, is a function of temperature and strain rate according to: ${ }^{[9-11]}$

$$
\hat{\sigma}_{\varepsilon s}=\hat{\sigma}_{\varepsilon s 0}\left(\frac{\dot{\varepsilon}}{\dot{\varepsilon}_{\varepsilon s 0}}\right)^{m}
$$

where $m=k T / g_{0 \varepsilon s} \mu b^{3}, \dot{\varepsilon}_{\varepsilon s 0}, g_{0 \varepsilon s}$, and $\hat{\sigma}_{\varepsilon s 0}$ are constants.

The shear modulus was calculated for face-centered cubic (FCC) materials using the formula:

$$
\mu=\sqrt{C_{44} \cdot\left(C_{11}-C_{12}\right) / 2}
$$

where $C_{i j}$ are the elastic constants ${ }^{[12]}$. For simplicity, an empirical equation ${ }^{[13]}$ was used to fit the data to incorporate the temperature dependence of " $\mu$ " in a form of:

$$
\mu=\mu_{0}-\frac{D}{\exp \left(\frac{T_{0}}{T}\right)-1} .
$$

The temperature-dependent shear modulus of $\mathrm{Al}$ was used here for $5182 \mathrm{Al}$.

\section{Solute Drag Regime}

The deformation mechanisms of $\mathrm{Al}$ and $\mathrm{Al}-\mathrm{Mg}$ alloys have been studied extensively in creep conditions ${ }^{[4-6]}$. Kocks and Chen ${ }^{[14]}$ have discussed the appropriate kinetic laws to describe deformation in the temperature/strain-rate regime where the solute drag mechanism dominates, and have shown how the appropriate descriptions of dislocation interactions and diffusion lead to the following expression for strain rate,

$$
\dot{\varepsilon}=A\left(\frac{\sigma}{\mu}\right)^{n} \frac{\mu b^{3}}{k T} \exp \left(-\frac{Q_{D}}{k T}\right)
$$

with $n=3$. In equation $12, Q_{D}$ is the activation enthalpy for self diffusion of $\mathrm{Mg}$ in aluminum (which is $131 \mathrm{~kJ} / \mathrm{mol}$ ), A is a pre exponential diffusion constant, and the other terms have their conventional meanings. If we rearrange terms in equation 12 and take the logarithm,

$$
\log \left(\frac{\sigma}{\mu}\right)=\frac{1}{n} \log \left[\frac{\dot{\varepsilon}}{s^{-1}} \frac{k T}{\mu b^{3}} \exp \frac{Q_{D}}{k T}\right]-\frac{1}{n} \log A .
$$

Thus, if we plot $\log (\sigma / \mu)$ vs. $\log \left[\left(\dot{\varepsilon} / s^{-1}\right)\left(k T / \mu b^{3}\right) \exp \left(Q_{D} / k T\right)\right]$ for our data, at different strain rates and temperatures, it will have a slope of $1 / 3$ (or a stress exponent $n=3$ ), if solute drag is the operative deformation mechanism.

\section{Results and Discussions}

The results that will be discussed focused on two areas: measurement of the stress/strain response of the $5182 \mathrm{Al}$ as a function of strain rate and temperature; and the compression deformation 
textures displayed in the specimens from which the stress/strain behavior was derived. The texture development is discussed elsewhere in this volume ${ }^{[15]}$.

\section{Mechanical Responses}

The stress/strain responses of $5182 \mathrm{Al}$ material are plotted in Figures 1 and 2 . Figure 1 shows the stress/strain curves of the $5182 \mathrm{Al}$ at low temperature and high strain rate. Figure 2 shows the stress/strain response of the $5182 \mathrm{Al}$ at high temperature and low strain rate. We have separated the mechanical behavior into two categories, when the materials display a yield point and when they do not.

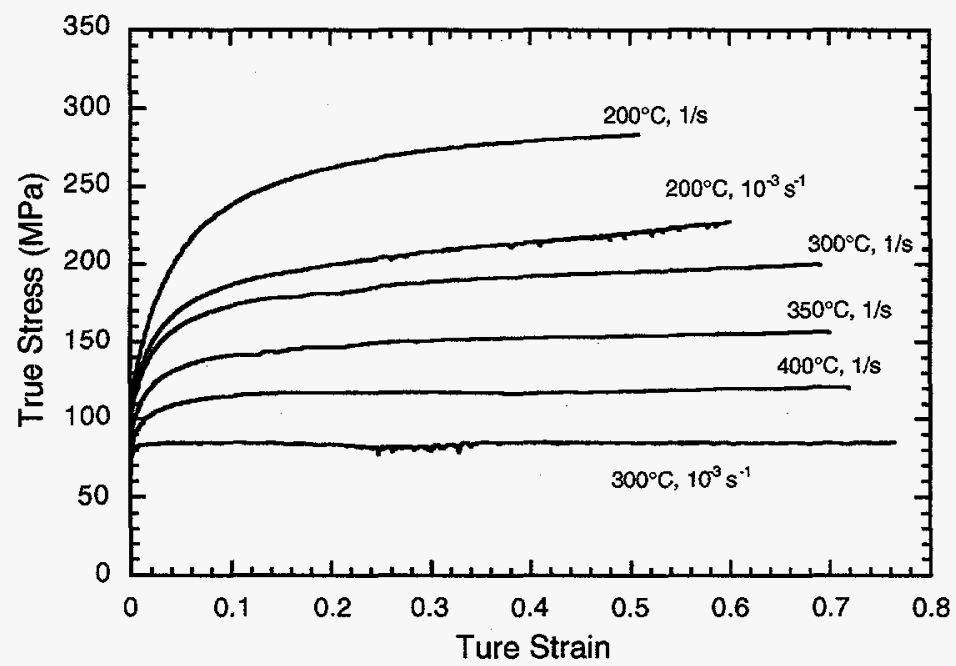

Figure 1: Compressive stress/strain response of the $5182 \mathrm{Al}$ at low temperature and high strain rate.

There is positive work hardening associated with flow behavior of the 5182 when the yield stress is above $80 \mathrm{MPa}$, Figure 1. For these experiments the yield stress was nearly constant. However the hardening and saturation flow stress increases with decreasing temperature and increasing strain rate. The data plotted in Figure 1 are all for material that has a positive strain-rate sensitivity.

One should note that if the yield point was observed, Figure 2, the yield stress was below 70MPa and the work-hardening curve was for practical purposes flat. The one exception to this was the

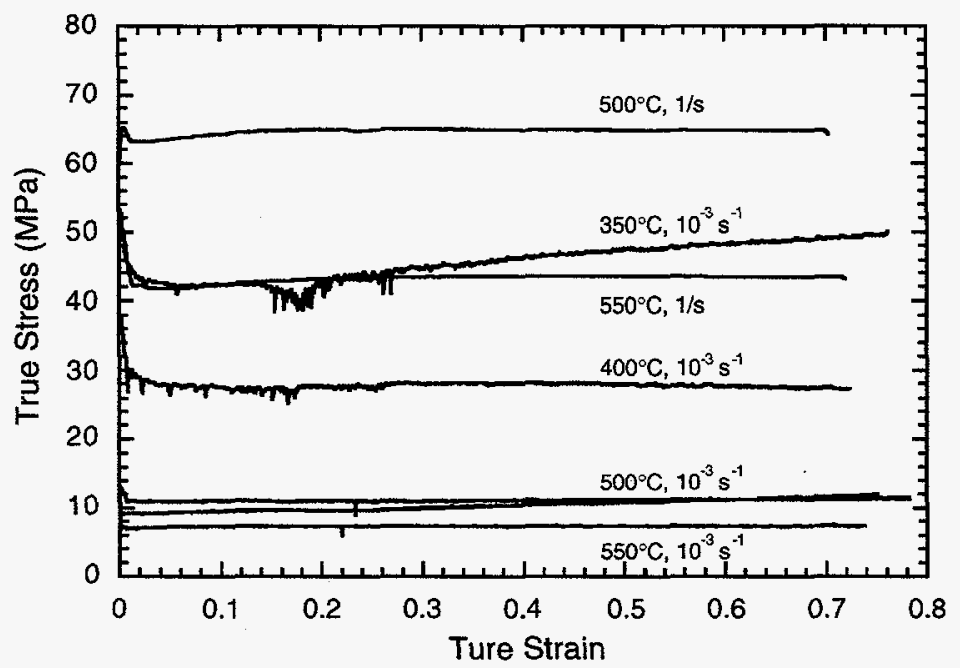

Figure 2: Compressive stress-strain response of $5182 \mathrm{Al}$ at high temperature and low strain rate. 
experiments run at $350^{\circ} \mathrm{C}$ and a strain rate of $10^{-3} \mathrm{~s}^{-1}$. In this case the flow curve had a short plateau, $\sim 10 \%$ strain, of no hardening and then the materials hardened continuously at a low rate. In addition to the hardening, the flow curve at this temperature and strain rate was very serrated. We believe that these particular effects are associated with fine $\mathrm{Mg}_{2} \mathrm{Si}$ precipitates going back into solution during the experiment. The yield point followed by no work hardening is associated with solute drag, by means of a diffusion process, occurring during deformation.

We have investigated the influence of the initial anisotropy on the mechanical properties by compressing samples in the rolling direction and in the plate normal direction. The result is shown in Figure 3. It is noted that the flow stresses obtained in two directions are basically the same that is consistent with the weak initial texture.

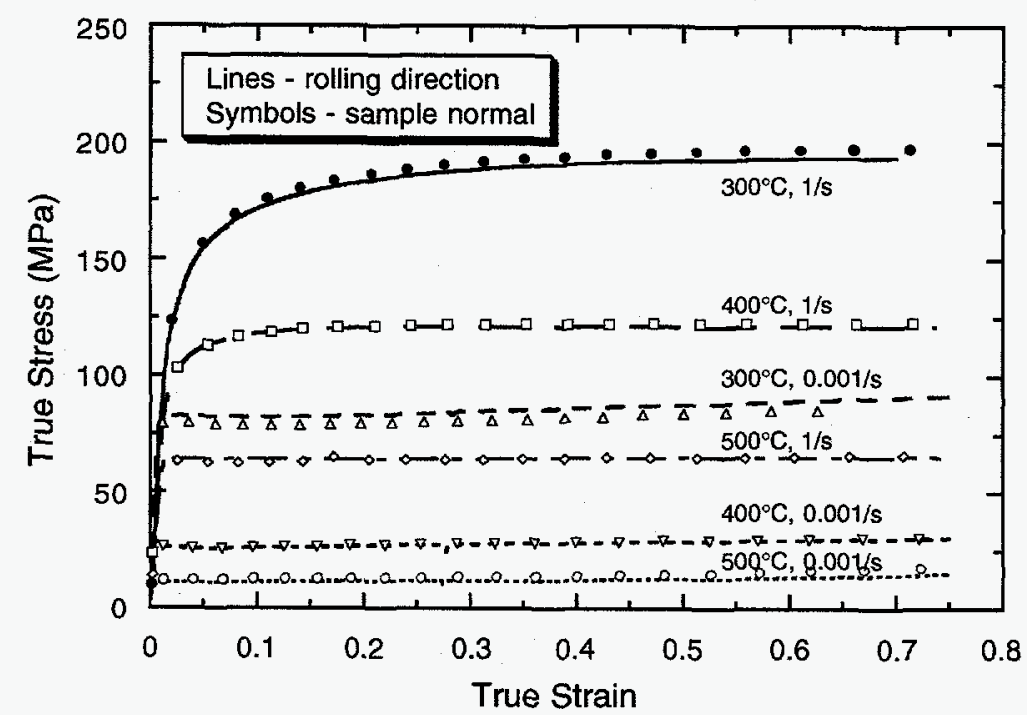

Figure 3: Compressive stress-strain response of the $5182 \mathrm{Al}$. The samples are deformed in the rolling direction (lines) and in the plate normal direction (symbols).

A set of selected curves, ranging from room temperature to $500^{\circ} \mathrm{C}$, and strain rates of $10^{-3} \mathrm{~s}^{-1}$ to $1 \mathrm{~s}^{-1}$, are plotted in Figure 4. At room temperature this material exhibits negative strain-rate sensitivity (top two curves in Figure 4). Dynamic strain aging, evidenced by the serrated flow curve, is the dominant deformation mechanism. Based on the stress/strain behavior we have

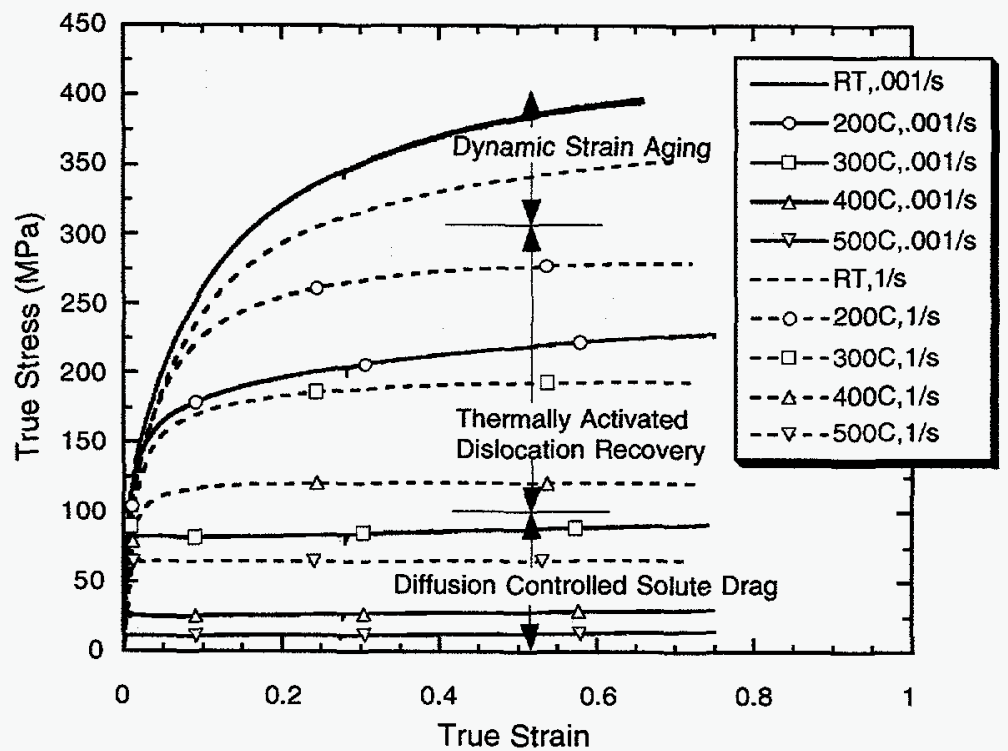

Figure 4: Compressive stress-strain response of the $5182 \mathrm{Al}$ as a function of temperature and strain rate. Regimes of different deformation mechanisms are shown. 
divided the mechanical response of the $5182 \mathrm{Al}$ into three regimes in terms of controlling deformation mechanisms as labeled in Figure 4. The demarcation line for each mechanism to operate depends on temperature and strain rate.

\section{Constitutive Modeling}

We have measured the yield strengths of the 5182 as a function of strain rate and temperature. In addition, saturation stress, as specified by the modified Voce hardening law (equation 8), was determined for each of the stress/strain experiments. Both of these forms of the data were correlated to a function of the test temperature and strain rate,

$$
\left[\frac{k T}{\mu b^{3}} \ln \left(\frac{10^{7} s^{-1}}{\dot{\varepsilon}}\right)\right]^{2 / 3} \equiv\left(\Delta G_{n o r m}\right)^{2 / 3}
$$

and plotted in Figure 5. In this equation $k$ is Boltzman's constant, $T$ absolute temperature, $\mu$ shear modulus, and $b$ the Burger's vector. In our analysis, $\dot{\varepsilon}_{0}=10^{7} s^{-1}, \mathrm{p}=1 / 2$ and $\mathrm{q}=3 / 2$ in equation 6 were chosen to unify the data obtained at various strain rates and temperatures into a single master curve.

In Figure 5 one observes three regions, referenced to the value of equation 14, each associated with different physical phenomenon of material behavior. When the value of $\left(\Delta G_{n o r m}\right)^{2 / 3}$ is less than about 0.32 the 5182 experiences dynamic strain aging and the associated negative strain-rate sensitivity. This is identified from the lower yield strength at room temperature than $200^{\circ} \mathrm{C}$ at a comparable strain rate of $\dot{\varepsilon}=1 \mathrm{~s}^{-1}$.

The 5182 experiences a solute drag, the continuous motions of dislocations is accompanied by solute diffusion, deformation mechanism at high temperatures and low strain rates. From our data, this begins when $\left(\Delta G_{n o r m}\right)^{2 / 3}$ is greater than 0.5 . One can see that the yield and saturation stresses are equal for this regime (zero material work hardening), indicative of the operative solute drag mechanism. One exception to this observation is the datum point at $350^{\circ} \mathrm{C}$ and a

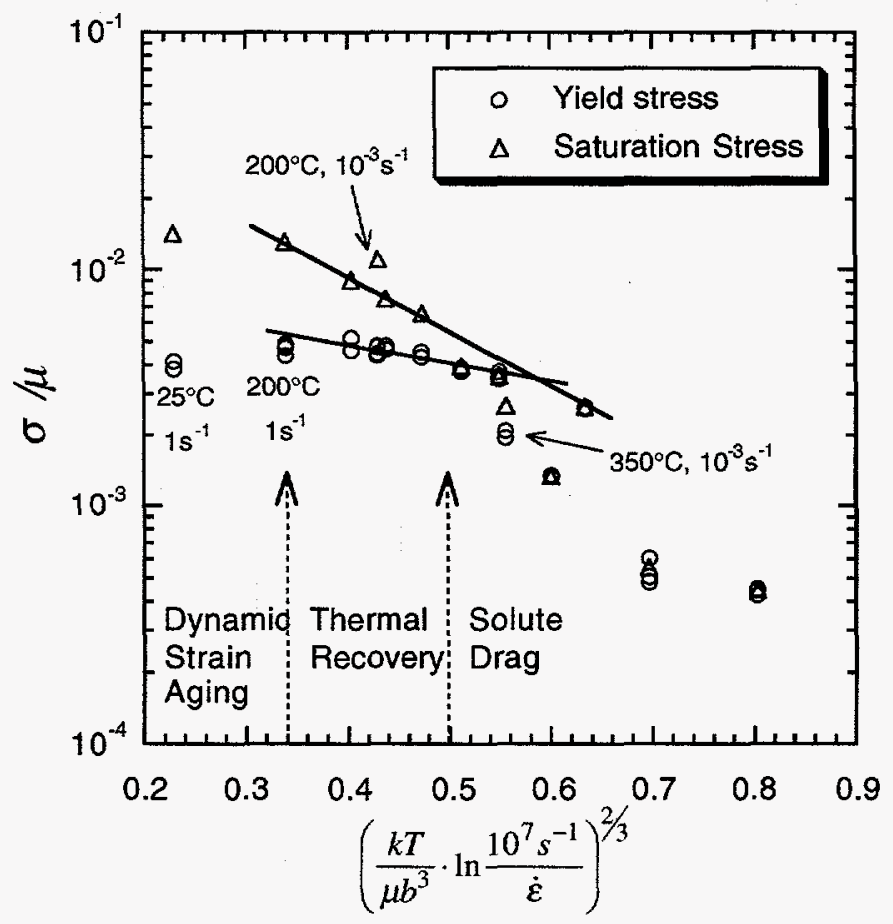

Figure 5: Yield and saturation stress measurements for the 5182 material. Regimes of different deformation mechanisms are shown. 
strain rate of $10^{-3} \mathrm{~s}^{-1}$. Again we believe that this anomaly is a result of $\mathrm{Mg}_{2} \mathrm{Si}$ precipitates dissolving and the material going into solution. One also notes that this collection of data do not lie on a single line, as would be expected if the deformation mechanism would be purely thermal recovery.

For conditions $0.34<\left(\Delta G_{n o r m}\right)^{2 / 3}<0.5$ we are in a strain-rate/temperature regime that is dominated by thermal recovery. The material experiences both positive work hardening and strain-rate sensitivity. The yield stress data lie nearly on a single line with a slightly negative slope (indicated by the lower solid line in Fig. 5) - one should not take the datum point at $200^{\circ} \mathrm{C}$ at $1 \mathrm{~s}^{-1}$ literally. The value of the negative slope is analogous to the Gibb's free energy for the recovery process. It is within this region that the Mechanical Threshold Strength (MTS) model is applicable. The detail of deriving parameters for this model have been published elsewhere for copper ${ }^{[3]}$ and for tantalum ${ }^{[16]}$. Figure 1 shows a regime with positive strain-hardening rate associated with flow behavior of the 5182. The MTS model is suitable to describe the temperature and strain-rate sensitivity of the yield and flow stresses. The model fitting result is shown in Figure 6. At $300^{\circ} \mathrm{C}$ and $0.001 \mathrm{~s}^{-1}$, the calculated flow stress is higher than the experimental data. The flat strain-hardening behavior indicates that it falls into the solute drag regime where the constitutive equation described in next section is more suitable to use. Overall the MTS model captures the strain hardening behavior and the temperature and strain-rate sensitivity reasonably well. The calculated stress for a test at $200^{\circ} \mathrm{C}$ and $0.001 / \mathrm{s}$, however, deviates substantially from

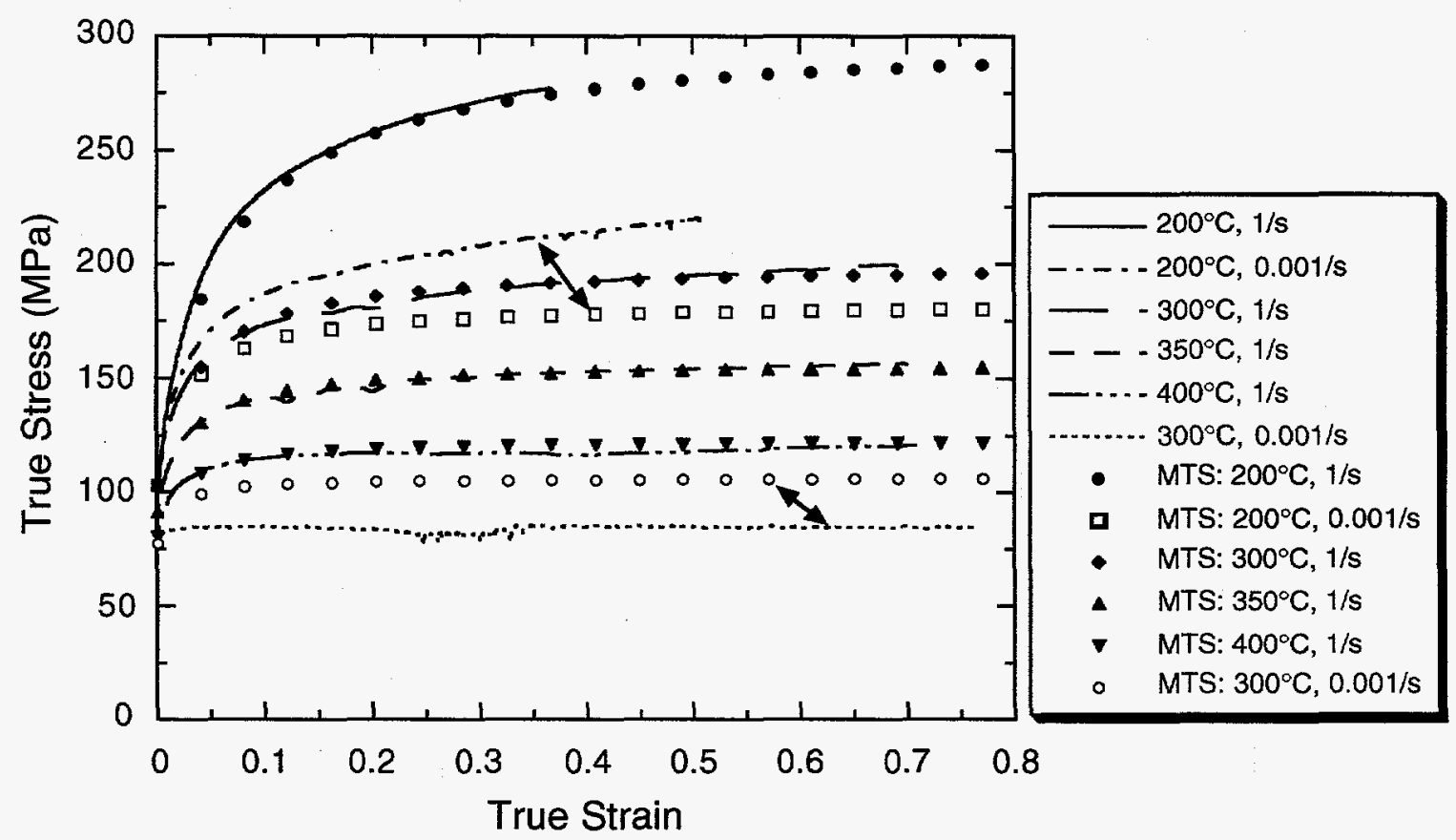

Figure 6: The stress/strain responses and the Mechanical Threshold Strength (MTS) model fit (symbols) for a 5182 aluminum alloy.

experimental data as indicated by arrows in Figure 6. We believe the enhanced strain-hardening rate at this temperature and strain rate is due to dynamic strain aging. A strain-rate jump test at this condition should be performed to verify this hypothesis. The constants of the MTS model for the $5182 \mathrm{Al}$ are summarized in Table I. These constants have been used by Korzekwa and Beaudoin ${ }^{[2]}$ in the calculation regarding hot rolling of this material.

\section{Solute Drag Regime}

In the high-temperature and low strain-rate regime, it has been shown that solute drag is the dominant deformation mechanism in many $\mathrm{Al}-\mathrm{Mg}$ alloys ${ }^{[4-6]}$. Our data plotted according to equations 12 and 13, based on solute drag mechanism, are shown in Figure 7. We found that the data can be approximated by a linear relation for values of $\log \left[\left(\dot{\varepsilon} / s^{-1}\right)\left(k T / \mu b^{3}\right) \exp \left(Q_{D} / k T\right)\right]<7.17$. 
Also, from a least square fit the slope taken by the data is very close to $1 / 3$. Based on these results, the formalism of equation 12 is appropriate for the 5182 in the highest regime of temperatures. The demarcation between the regime of solute drag and thermal recovery, as illustrated by the data in Figure 7, is particularly dramatic.

Table I Parameters for the MTS model

\begin{tabular}{|c|c|c|c|c|c|c|c|}
\hline Equation & Parameter & Value & Unit & Equation & Parameter & Value & Unit \\
\hline (3) & $\sigma_{a}$ & 10 & $\mathrm{MPa}$ & \multirow{2}{*}{$\begin{array}{c}(8) \\
\theta\end{array}$} & $\theta_{0}$ & 6800 & $\mathrm{MPa}$ \\
\hline$\sigma$ & $\hat{\sigma}_{i} / \mu_{0}$ & 0.010315 & - & & $\kappa$ & 2 & - \\
\hline \multirow{4}{*}{$\begin{array}{c}(3),(6) \\
S_{i}\end{array}$} & $g_{0 i}$ & 1.196 & - & \multirow{3}{*}{$\begin{array}{l}(9) \\
\hat{\sigma}_{\varepsilon s}\end{array}$} & $g_{0 \varepsilon s}$ & 0.1058 & - \\
\hline & $\dot{\varepsilon}_{0 i}$ & $10^{7}$ & $\mathrm{~s}^{-1}$ & & $\hat{\sigma}_{\varepsilon s 0}$ & 1996 & $\mathrm{MPa}$ \\
\hline & $q_{i}$ & $3 / 2$ & - & & $\dot{\varepsilon}_{0 \varepsilon s}$ & $10^{7}$ & $\mathrm{~s}^{-1}$ \\
\hline & $p_{i}$ & $1 / 2$ & - & & $k / b^{3}$ & 0.5899 & $\mathrm{MPa} / \mathrm{K}$ \\
\hline \multirow{4}{*}{$(3),(6)$} & $\dot{\mathcal{\varepsilon}}_{0 \varepsilon}$ & $10^{7}$ & $\mathrm{~s}^{-1}$ & & $b$ & $2.86 \times 10^{-10}$ & $\mathrm{~m}$ \\
\hline & $g_{0 \varepsilon}$ & 1.6 & - & \multirow{3}{*}{$\begin{array}{c}(11) \\
\mu\end{array}$} & $\mu_{0}$ & 28815 & $\mathrm{MPa}$ \\
\hline & $q_{\varepsilon}$ & 1 & - & & $D$ & 3440 & $\mathrm{MPa}$ \\
\hline & $p_{\varepsilon}$ & $2 / 3$ & - & & $T_{0}$ & 215 & $\bar{K}$ \\
\hline
\end{tabular}

In the solute drag regime an appropriate constitutive relation, accounting for the exponent being slightly different than 3 and evaluating $\mathrm{A}$, is:

$$
\log \left(\frac{\sigma}{\mu}\right)=0.274 \cdot \log \left(\frac{\dot{\varepsilon}}{s^{-1}} \frac{k T}{\mu b^{3}} \exp \frac{Q_{D}}{k T}\right)-4.416
$$

The average stress exponent $n$ within this regime is 3.65. In Figure 7, we include a line (dashed) that indicates a stress exponent of 3 and an activation energy $\left(Q_{D}\right)$ of $131 \mathrm{~kJ} / \mathrm{mol}$ would be. The

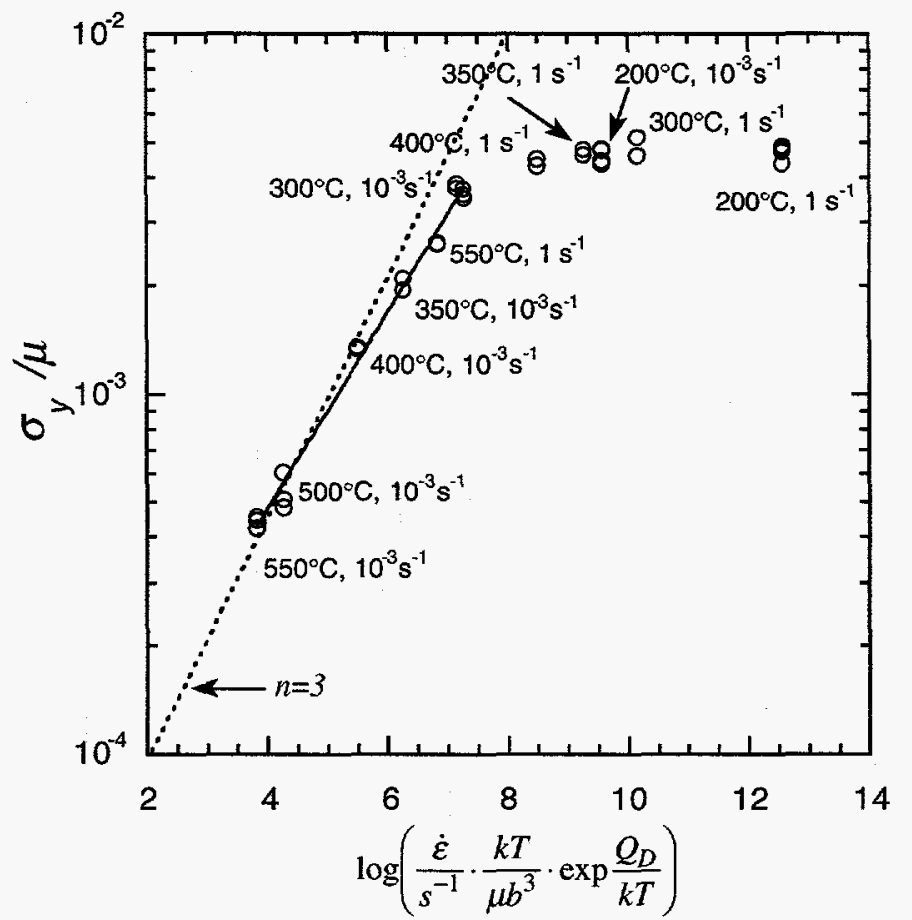

Figure 7: Yield stress data for the $5182 \mathrm{Al}$ plotted appropriately for the equations that govern the deformation in the solute drag regime. 
slope fitted to the experimental data is so close to $1 / 3$ that at higher-temperature and low strainrate regime the solute drag appears to be the dominant deformation mechanism. However, the practical approach will be the use of equation 15 (solid line in Figure 7).

We have conducted a few interrupt tests at $400^{\circ} \mathrm{C}$ at $10^{-3} \mathrm{~s}^{-1}$ to study the possibility of microstructure change, namely recrystallization, which leads to the development of a cube texture component. Samples were deformed to $\varepsilon \sim 0.5$, then the test was interrupt to unload the sample. Each sample was held at test temperature for different amounts of time (3,10,60, or $300 \mathrm{sec})$. The sample was then deformed further, another $20 \%$ of strain. The original traces of load versus time are plotted in Figure 8(a) for three tests with holding time of 10, 60, and $300 \mathrm{sec}$. The truestress/plastic-strain responses are plotted in Figure 8(b). Excellent reproducibility among tests is seen in Figure 8. The flow stress shows an inverse transient in the early part of straining and keeps at a constant level for the remaining of the test. The flow stress immediately after reloading, with or without inverse transient, reaches the level just before the sample was unloaded. The lack of change in strength indicates that insignificant/no microstructural change occurred during holding at temperature. This also supports the hypothesis that the majority of the

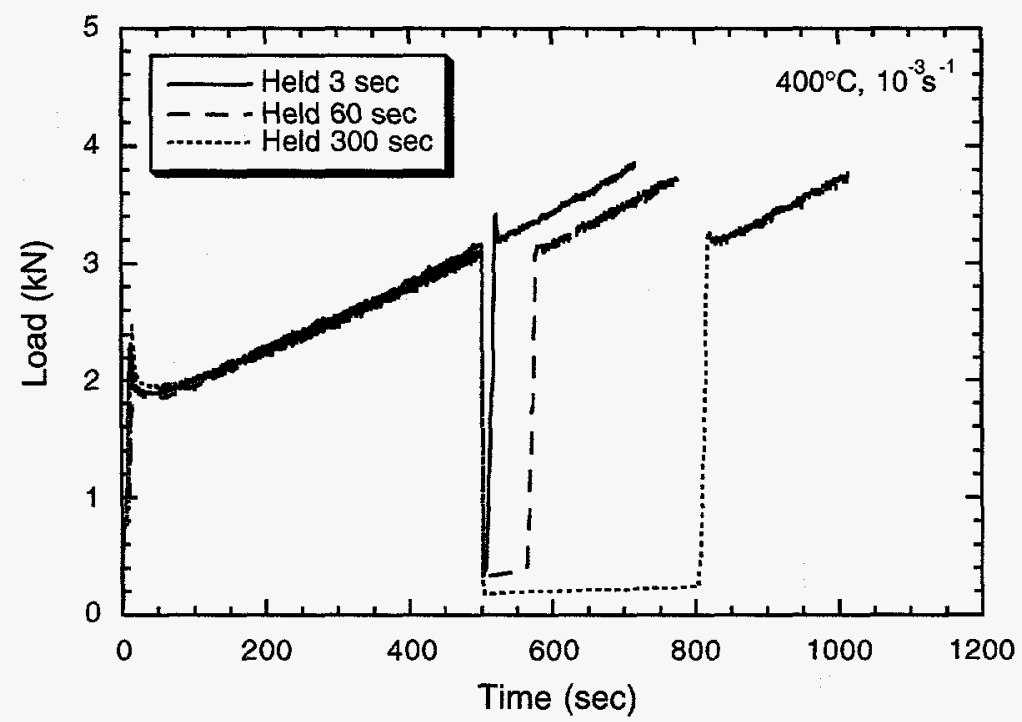

(a)

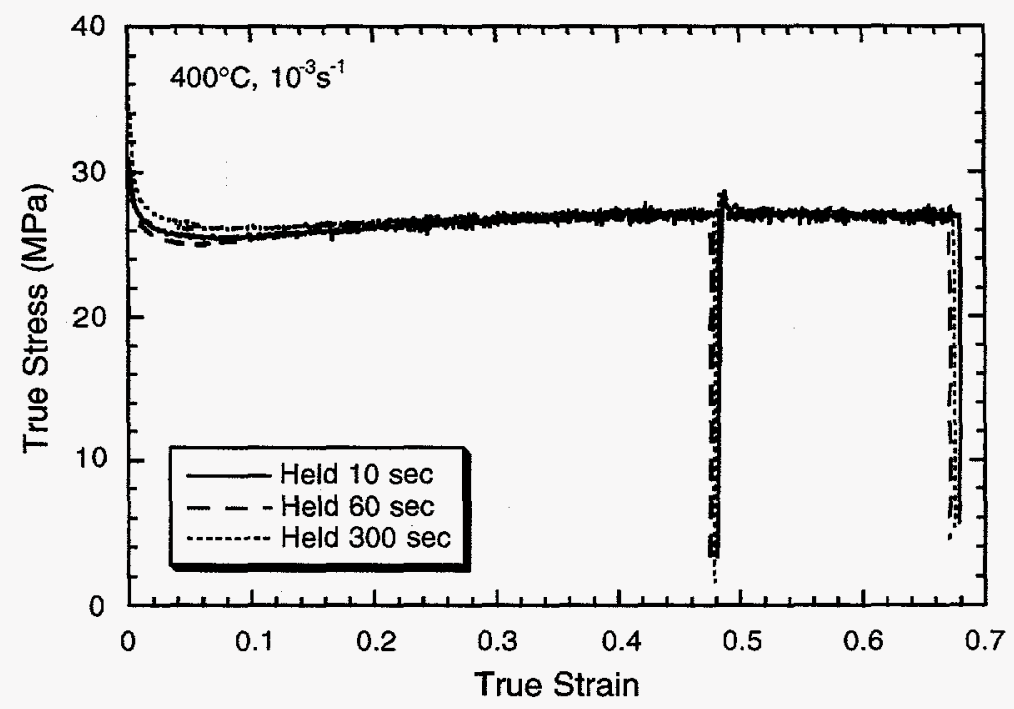

(b)

Figure 8: Stress/strain responses of $5182 \mathrm{Al}$ deformed at $400^{\circ} \mathrm{C}$ at $10^{-3} \mathrm{~s}^{-1}$. At $\varepsilon \sim 0.5$, the sample was unloaded and held at temperature for various amount of time: (a) load versus time plot, and (b) true stress/strain plot. 
dislocations present in the material are mobile in the solute drag regime leading to the derivation of equation 12.

When there is positive work hardening (Figure 1), it is expected that static recrystallization may occur if given sufficient amount of time at high temperature. This is the situation observed during hot rolling process between each stand. The effect of the softening on the constitutive relations needs to be addressed.

\section{Summary}

The current study of the mechanical properties and constitutive relation for a 5182 aluminum alloy under high-temperature deformation yields the following conclusions:

(1). Three regimes, each having a different dominant deformation mechanism, have been identified during our study of the mechanical behavior of this material. At the lower normalized activation energy regime (room temperature, low strain rate), dynamic strain aging is observed. Increasing test temperature leads to a regime where deformation is governed by dislocation accumulation and dynamic recovery based on thermal activated processes. At even higher temperature and low strain-rate conditions, solute drag becomes the dominant deformation mechanism evidenced by practically no work hardening.

(2). In the thermally activated regime, the constitutive response as a function of temperature and strain rate can be described accurately by the Mechanical Threshold Strength (MTS) model.

(3). When the yield stress was below $70 \mathrm{MPa}$, the deformation achieved by continuous motion of dislocations accompanied by diffusion of solute. Within this regime a power-law constitutive relation with a stress exponent $(n)$ of 3.65 and an activation energy $\left(Q_{D}\right)$ of 131 $\mathrm{kJ} / \mathrm{mol}$, which is the activation enthalpy for self diffusion of $\mathrm{Mg}$ in aluminum, is found to be adequate in unifying the yield/saturation stress.

\section{Acknowledgements}

The authors acknowledge the assistance of M.L. Lovato, R.W. Ellis for conducting the mechanical tests. This study was supported by the U.S. Department of Energy, Basic Energy Sciences, Division of Materials Sciences.

\section{References}

1. P.J. Maudlin, R.F. Davidson, and R.J. Henninger, "Implementation and Assessment of the Mechanical-Threshold-Stress Model Using the EPIC2 and PINON Computer Codes", (Report LA-11895-MS, Los Alamos National Laboratory, 1990).

2. D.A. Korzekwa and A.J. Beaudoin, "Modeling the Effect of Friction and Geometry on Deformation Path during Hot Rolling of Aluminum", Hot Deformation of Aluminum Alloys II, T.R. Bieler, S.R. MacEwen, and L. Lawrence, eds., The Minerals, Metals \& Materials Society, (1998), in press.

3. P.S. Follansbee and U.F. Kocks, "A Constitutive Description of Copper Based on the Use of the Mechanical Threshold Stress as an Internal State Variable", Acta metall., 36, (1988), 81-93.

4. H. Oikawa and T.G. Langdon, "The Creep Characteristics of Pure Metals and Metallic Solid Solution Alloys", Creep Behaviour of Crystalline Solids, B. Wilshire and R.W. Evans, eds., (Swansea: Pineridge Press, 1985), pp. 33-82.

5. H. Oikawa, "Creep Behavior of Simple Solid Solutions of Aluminum", Hot Deformation of Aluminum Alloys, T.G. Langdon, H.D. Merchant, J.G. Morris, and M.A. Zaidi, eds., The Minerals, Metals \& Materials Society, (1991), 153-180.

6. W. Blum, "Creep of Aluminum and Aluminum Alloys", Hot Deformation of Aluminum Alloys. T.G. Langdon, H.D. Merchant, J.G. Morris, and M.A. Zaidi, eds., The Minerals, Metals \& Materials Society, (1991), 181-209.

7. Rastegaev, "A New Method of Homogeneous Compression of Specimens for Determining Flow Stress and the Coefficient of Internal Friction", ZADOVSK LAB., 6, (1940), 345. 
8. U.F. Kocks, A.S. Argon, and M.F. Ashby, Thermodynamics and Kinetics of Slip, Progress in Materials Science, 19, (Pergamon Press, New York, 1975).

9. U.F. Kocks, "Laws for Work-Hardening and Low-Temperature Creep", J. Eng. Mater. Tech. Trans. ASME, 98, (1976), 76-85.

10. P. Hassen, "Plastic Deformation of Nickel Single Crystals at Low Temperatures", Phil. Mag., 3, (1958), 384-418.

11. G. Schoeck and A. Seeger, Defects in Crystalline Solids, (Physical Society, London, 1955).

12. G. Simmons and H. Wang, Single Crystal Elastic Constants and Calculated Aggregate Properties: A Handbook, 2nd edn., (The M.I.T. Press, Boston, Mass., 1991).

13. Y.P. Varshni, "Temperature Dependence of the Elastic Constants", Phys. Rev. B, 2, (1970), 3952-3958.

14. U.F. Kocks and S.R. Chen, "Constitutive Laws for the Deformation and Dynamic Recrystallization in Cubic Metals", the 7th JIM International Symposium (JIMIS-7) on Aspects of High Temperature Deformation and Fracture in Crystalline Materials. Y. Hosoi, Yoshinaga, and H. Oikawa, eds., The Japan Institute of Metals, (1994), 593-600.

15. M.G. Stout, et al., "Mechanisms Responsible for Texture Development in a 5182 Aluminum Alloy Deformed at Elevated Temperature", Hot Deformation of Aluminum Alloys II. T.R. Bieler, S.R. MacEwen, and L. Lawrence, eds., The Minerals, Metals \& Materials Society, (1998), in press.

16. S.R. Chen and G.T. Gray, III, "Constitutive Behavior of Tantalum and Tantalum-Tungsten Alloys", Metall. Trans. A, 27A, (1996), 2994-3006. 